\title{
Design and Potential Analysis of Regenerative Braking in Electric Bike
}

\author{
Rohit Pandey
}

Assistant Professor, Mechanical Engineering Department, Amity University Madhya Pradesh, Gwalior M.P.-474005, India.

To Cite this Article

Rohit Pandey, "Design and Potential Analysis of Regenerative Braking in Electric Bike”, International Journal for Modern Trends in Science and Technology, Vol. 06, Issue 06, June 2020, pp.:10-13; https://doi.org/10.46501/IJMTST060603

\section{Article Info}

Received on 26-April-2020, Revised on 22-May-2020, Accepted on 25-May-2020, Published on 28-May-2020.

\section{ABSTRACT}

The genesis of idea behind this research paper is to promote the use of transportation system in our society that is eco friendly in terms of air pollution as Ill as is affordable by every person of the society. Apart from this I felt that now it's the high time to switch to non-conventional transportation system as soon as possible so that the rapidly increasing risk of natural devastation can be controlled and reduced to an acceptable limit. Gone Ire the days where I only think and learn about the non-conventional approaches of transportation, our project aims to build a positive outlook in the minds of consumers that its equally good to use electric vehicles and to encourage people to switch to greener solutions.

KEYWORDS: Electric bike, Regenerative Braking, Waste Energy Regeneration, non-conventional, Efficiency.

Copyright (0) 2014-2020 International Journal for Modern Trends in Science and Technology

DOI: https://doi.org/10.46501/IJMTST060603

\section{INTRODUCTION}

Loss of power and efficiency in electrical and mechanical systems has been a recurring problem in automotive design. In recent years, energy regeneration has made rapid advances in the automotive world. Regenerative braking is defined by the United States Department of Energy as a system that captures the energy lost during braking by utilizing an electric motor as a generator and storing the energy captured. This extra energy is re-used during acceleration, providing the vehicle with more energy and a longer range. Energy regeneration is not only a concept that has been applied to automobiles, but also on a smaller scale to motorcycles, motorbikes and scooters. 1 With renewable and regenerative energy remaining a relatively new and expensive model, small scale regenerative systems can be minor steps toward a more eco-friendly lifestyle. Regenerative motorbikes are not a necessarily new concept; However there is still room for improvement in their efficiency, design and adaptability. According to the Massachusetts Registry of Motor Vehicles (RMV), a motorbike can operate with or without pedals, has an automatic transmission, runs on some form of electric motor, does not operate above $30 \mathrm{mph}$ and requires a minor registration and titling by an operator with a valid driver's license.

\section{METHODOLOGY}

The idea behind making a setup based upon Regenerative Braking System (RBS) was quite clear, interesting and a challenging one as the area in which are Ire investing our time and efforts was untouched till now, therefore I was very clear about the methodology that I am going to adapt in the making of the braking setup. This quote was not a mere motivation but an alarm to us as this was even applicable to our making of the setup. I knew 
that directly getting in the workshop and start machining the work/job and components may lead us to situation where I would get to realize that our investment in the setup in terms of money, time and progress is not worth up to the mark. Therefore I have decided to follow a three stage process to build the Regenerative Braking setup:

Stage I: Designing Stage

Stage II: Manufacturing Stage

Stage III: Analysis and Testing Stage

All the above mentioned stages are discussed in details in the later sections of this article.

\subsection{Stage I: Designing Stage}

Designing stage is the most vital and important stage in the complete manufacturing process as designing the whole model/setup on virtual platforms like AutoCAD, Solid Works and other designing software's give us a fair idea about their feasibility. I calculated and jotted down all the dimensional specifications of different units and components going to be used in the making of the setup. Along with that I began planning a proper layout of the setup on paper and keeps it improvising unit I get the best and suitable layout where all the units and components can be accommodated correctly. Designing these days in the most powerful tool that gives an extra edge to the manufacturers providing idea about all the physical standards of the setup like its appearance, dimensions, strength and etc. It is widely in use as it computes data quickly and are 100\% accurate being based upon the computers. It process the given input so greatly that each and every single detail about the setup can be seen and analyzed on computers without wasting even a single penny in creating a prototype of the same and then conducting the specific tests on the prototype, this saves both time and money. I started the designing and completed it, later I examined and tested the design that I had on testing software Ansys where I got satisfying results within the limits of acceptable standards and hence our design was approved and I got a green flag to proceed further.

\subsection{Stage II: Manufacturing Stage}

Once I got clearance at the designing level, there comes the most difficult task of building the Regenerative Braking setup at hand. I was excited and nervous too as I Ire about to start

the real visible and tedious job in the making of the braking setup. I started off with arranging all the necessary raw materials, tools (including hand tools and different hand held gauges) fixing materials and a good place to work. After gathering all the necessary things I kicked of the manufacturing with full boast and a hope of success. In our beginning stage I first build the rectangular base truss using steel tubes and then worked upon the base land and extension legs. For proper measurement I use the basic technique of drawing the draft on the floor using a chalk and then assembling the units as per the measurements. Then the main task came next to our doors of knowledge, where I Ire supposed to start mounting the upper mounts for the rotating wheel (replica of wheel in vehicle), motor and complete brake mechanism including regenerative braking unit and the brake paddle. 28 I first mounted the brake unit and fixed all their corresponding components on them and further proceeded to mount the rotating wheel and motor on the top section of the setup, but I failed and our calculations Int wrong. Then I decided to refit the brake unit a little behind its original position on the top section by cutting the wed and re-wedding it to the desired location. On completion of manufacturing I proceeded further and make all necessary connection of electrical components and the braking unit. Finally, our efforts paid us in terms of a complete setup that was working on Regenerative Braking system.

\subsection{Stage III: Analysis and Testing Stage}

Analysis and testing stage Ire the real stage where our efforts will be put to the test and getting satisfactory results was must. I started the testing on the model of Regenerative Braking setup by comparing it with existing conventional models. Knowing the technical specification of the components, I calculated the total number of kilometres that the model will move (i.e. the total wheel's rotation) individually in the case of incorporation of Regenerative Braking system and even without the regenerative braking system. The result that I got was quite satisfying and its actual calculations are mentioned below:

\section{(i) Technical Specifications}

(a) Battery: 12V (volts), 7.2Ah (Ampere-hours)

(b) DC Motor: $50 \mathrm{~W}$ BL DC-Motor, 1500 RPM

(c) Dynamo: $12 \mathrm{~V}$ (volts), $100 \mathrm{RPM}$

\section{(ii) Calculations}

The calculations for the analysis of the setup are mentioned below:

- Diameter of the rotating wheel $(\mathrm{D})=0.2073 \mathrm{~m}$

- Distance covered by the wheel in one revolution = Circumference of the wheel 
$\prod^{*} \mathrm{D}=0.64 \mathrm{~m}$

RPM of the DC Motor $(\mathrm{N})=1500$ RPM

- Speed of the wheel $(\mathrm{S})=0.64 * \mathrm{~N}=900 \mathrm{~m} / \mathrm{min}=$ $16 \mathrm{~m} / \mathrm{s}$

- Therefore speed of the wheel $=16 \mathrm{~m} / \mathrm{s}$

Time taken by the battery for complete discharge* $(\mathrm{T})=48$ minutes.

* Battery was fully charged, Battery discharges uniformly and Battery was left undisturbed when motor starts rotating. Total distance covered/travelled by the wheel in complete discharge of the battery $=$ Speed of the wheel $(\mathrm{S})^{*}$ Time Taken $(\mathrm{t})=16^{*} 48^{*} 60=46080 \mathrm{~m}$ Therefore total distance travelled $=46.08 \mathrm{~km}$ These results Ire recorded when the model was run without Regenerative Braking system and further results Ire recorded when model was run incorporating the Regenerative Braking system and there was a significant hike in the total distance travelled by the wheel when the setup was run using the Regenerative Braking system.

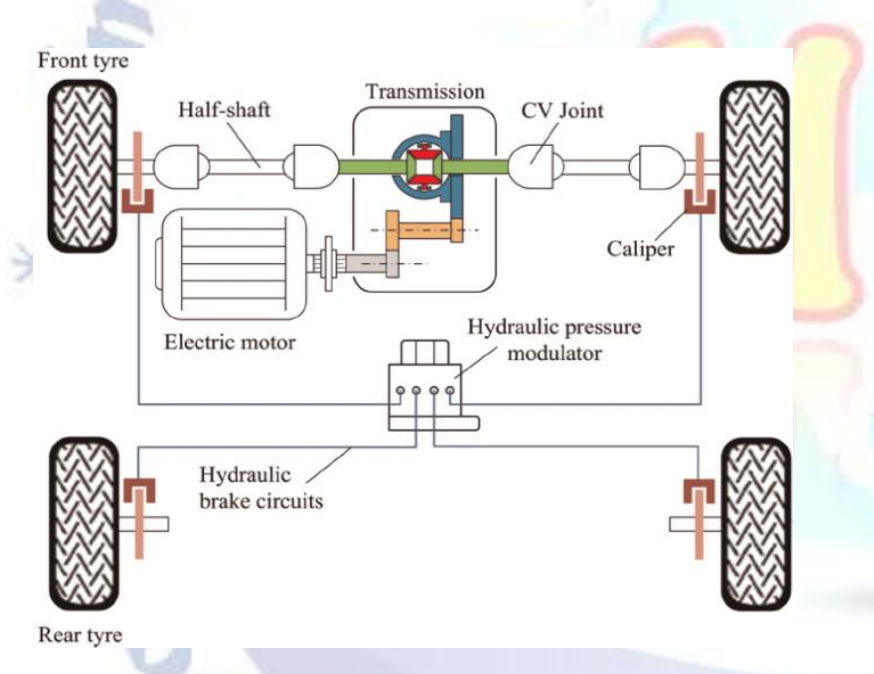

Figure 1: Regenerative braking system design

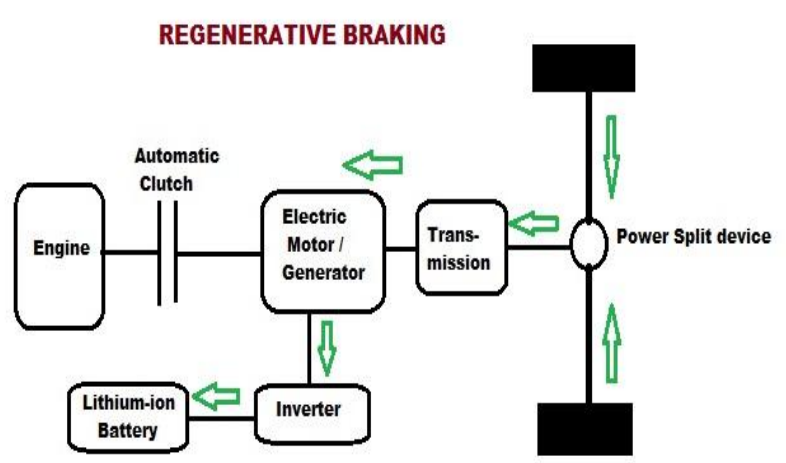

Figure 2: Regenerative braking system in electric vehicle.

\section{RESULTS AND DISCUSSION}

The result that I got from this course was achievement of our goals and aims in terms of acquisition of deep knowledge of manufacturing industry, their working procedures, planning behind every action and execution of plans without compromising on time range allotted. Electric bikes are already available in the market but they have certain limitations. These limitations are countered in our study and better alternatives for them Ire found. I have also conducted an extensive market survey digitally about the available designs, properties, specifications of e-bikes so that regenerative braking systems can be incorporated in them based upon their requirements and varying load carrying capacity. After the theoretical study of the topic, I feel our self-rich in terms of knowledge of electric vehicles especially e-bikes and their current operational situations along with problems and issues related to them. I even got an idea about the changing consumer demands in the present market scenario and ways to deal them. It was a major challenge in front of us to build setup based on Regenerative Braking system that has some positive efficiency and must stand as value for money item. I was very concerned about the results of this braking system as e-bikes with regenerative braking system was never put to test earlier and so getting significant results and a good hike in terms of efficiency was the prime goal of building the setup rather than just to demonstrate the phenomenon of energy regeneration. From this project, I even emphasize on the fact of Waste Energy Management (IM). IM is the technique of utilizing some portion of the waste energy to generate some sort of productive energy that can be consumed in different ways. This ensures energy regeneration and a step towards sustainable development. I even get to know that there's no limit of knowledge while going through the theory of the topic and even understood the tough concepts through small laboratory experiments.

\section{CONCLUSION AND FUTURE PROSPECTS}

The genesis of idea behind our project is the promotion of greener solution with an extra edge of waste energy management (IM) which is very much needed for the mankind and the society. With the increasing and alarming situation of pollution, depletion of fossil fuels, increase in greenhouse gases the electric bikes are the future bikes and has grown rapidly in the 21st century. Manufacturing prototypes of such e-bikes 
incorporating Regenerative Braking in them has given us the real understanding of vehicle manufacturing and proved to be a remarkable achievement at this level, enabling us to apply our theory knowledge on practical grounds. The future of manufacturing industries and more specifically the electric vehicle industry is very enormous and therefore, traditional diesel or petrol engines are being overtaken by electric and hybrid vehicles. If taken into account about the current changing situation of Indian market and consumers of automobiles, e-bikes is the new trend and every big manufacturing firm is investing in it, with the Regenerative Braking getting into assistance along with these e-bikes their future is great and will find its place in every home as a mode of convenient, economical, long-lasting, eco-friendly mode of transportation.

\section{ACKNOWLEDGEMENT}

Author would like to thank Amity University for giving such a wonderful research facility to do this research work and giving valuable Experimental facility to complete this research work and also thank to my Ph.D Supervisor to support and guide me for this research paper work.

\section{REFERENCES}

[1] Duran, A.; Earleywine, M. GPS data filtration method for drive cycle analysis applications. In Proceedings of the SAE 2012 World Congress \& Exhibition, Detroit, MI, USA, 24-26 April 2012; SAE: Warrendale, PA, USA, 2012.

[2] Justin, D.K.; Axon, C.J. A robust, data-driven methodology for real-world driving cycle development. Transp. Res. Part D Transp. Environ. 2012, 17, 389-397.

[3] Kamble, S.H.; Mathew, T.V.; Sharma, G.K. Development of real-world driving cycle: Case study of Pune, India. Transp. Res. Part D Transp. Environ. 2009, 14, 132-140.

[4] Hung, W.T.; Tong, H.Y.; Lee, C.P.; Ha, K.; Pao, L.Y. Development of a practical driving cycle construction methodology: A case study in Hong Kong. Transp. Res. Part D Transp. Environ. 2007, 12, 115-128.

[5] Haan, P.D.; Keller, M. Real-World Driving Cycles for Emission Measurement: ARTEMIS and Swiss Cycles; Final Reports; ResearchGate: Berlin, Germany, 2001.

[6] Hongwen, H.; Rui, X.; Jinxin, F. Evaluation of Lithium-Ion Battery Equivalent Circuit Models for State of Charge Estimation by an Experimental Approach. Energies 2011, 4, 582-598.

[7] Ruan, J.; Walker, P.D.; Watterson, P.A.; Zhang, N. The dynamic performance and economic benefit of a blended braking system in a multi-speed battery electric vehicle. Appl. Energy 2016, 183, 1240-1258.

[8] Genta, G.; Morello, L. The Automotive Chassis Volume 2: System Design; Springer: Dordrecht, The Netherlands, 2009; pp. 239-240, ISBN 978-1-4020-8673-1.

[9] Ehsani, M.; Gao, Y.; Ali, E. Modern Electric, Hybrid Electric and Fuel Cell Vehicles: Fundamentals, Theory, and Design, 2nd ed.; CRC Press: Boca Raton, FL, USA, 2009; ISBN 9781420053982.

[10] Zadeh, L.A. Fuzzy sets. Inform. Contr. 1965, 8, 338-353.
[11] Michels, K.; Klawonn, F. Fuzzy Control: Fundamentals, Stability and Design of Fuzzy Controllers; Springer: Berlin/Heidelberg, Germany, 2006; Volume 200, pp. 1-5, 243-245.

[12] Hájek, P. Metamathematics of Fuzzy Logic, 4th ed.; Springer: Dordrecht, The Netherlands, 1998; Chapter 4, pp. 35-45.

[13] Oleksowicz, S.A.; Burnham, K.J.; Southgate, A.; McCoy, C.; Waite, G.; Hardwick, G.; Harrington, C.; McMurran, R. Regenerative braking strategies, vehicle safety and stability control systems: Critical use-case proposals. Veh. Syst. Dyn. 2013, 51, 684-699.

[14] Zhang, J.; Lv, C.; Qiu, M.; Li, Y.; Sun, D. Braking energy regeneration control of a fuel cell hybrid electric bus. Energy Convers. Manag. 2013, 76, 1117-1124.

[15] Xiao, B.; Zeng, X.; Zhang, Z.; Li, B.; Yang, Y. Present status and prospect of the regenerative-braking control strategies of electric automobiles. Auto Electr. Parts 2016, 12, 1-3.

[16] Martin, R.; Richard, A.U.; Tilo, K.; Markus, L. Combining Regenerative Braking and Anti-Lock Braking for Enhanced Braking Performance and Efficiency. In Proceedings of the SAE 2012 World Congress \& Exhibition, Detroit, MI, USA, 24-26 April 2012; SAE: Warrendale, PA, USA, 2012.

[17] Juan, J.C.A.; Javier, P.F.; Juan, M.V.G.; Juan, A.C.C. Regenerative Intelligent Brake Control for Electric Motorcycles. Energies 2017, 10, 1648.

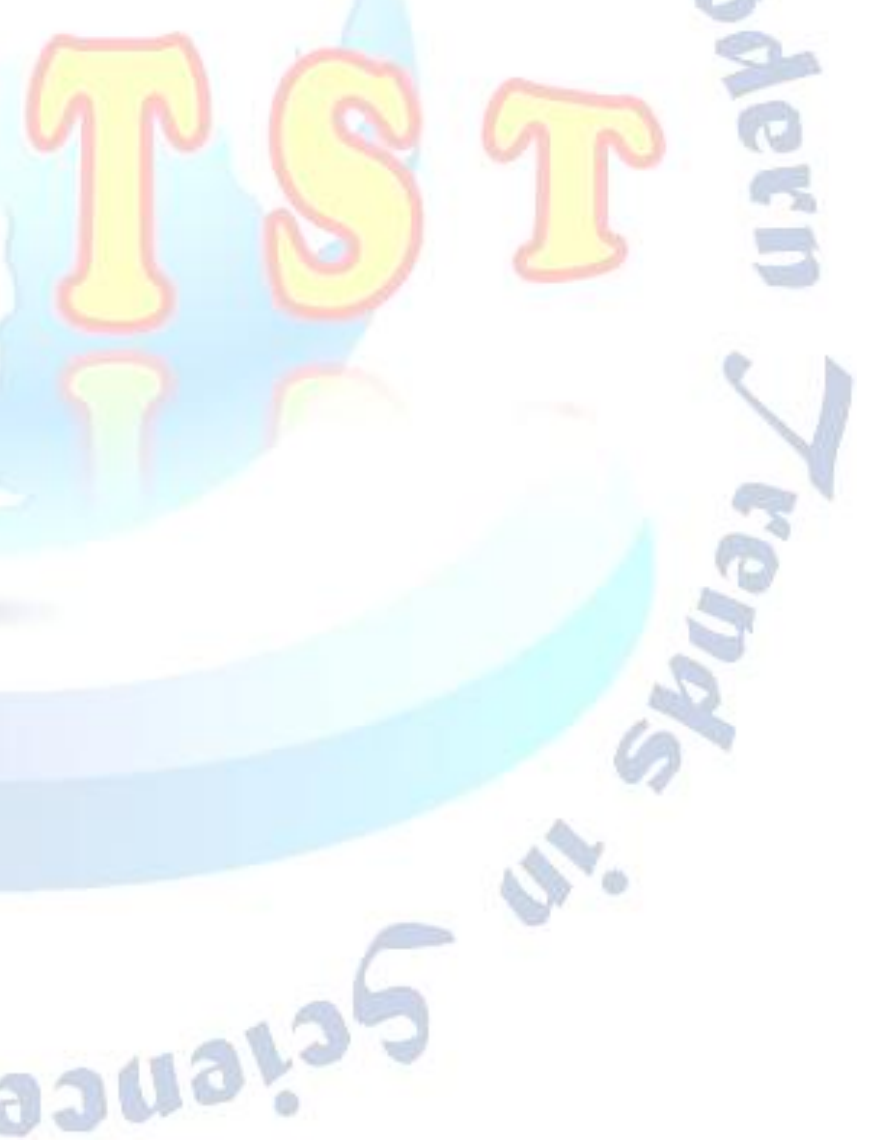

